Article

\title{
Implementation of an RFID-Based Sequencing-Error-Proofing System for Automotive Manufacturing Logistics
}

\author{
Yong-Shin Kang ${ }^{1, *}$, Hyoennam Kim ${ }^{2}$ and Yong-Han Lee ${ }^{3}$ \\ 1 Department of Systems Management Engineering, Sungkyunkwan University, 2066 Seobu-ro, Jangan-gu, \\ Suwon, Gyeonggi-do 16419, Korea \\ 2 ME Advanced Team, ME Center, GM Korea Company, 233 Bupyeong-daero, Bupyeong-gu, \\ Incheon 21334, Korea; hyeonnam.kim@gm.com \\ 3 Department of Industrial and Systems Engineering, Dongguk University-Seoul, 3ga, Pil-dong, Jung-gu, \\ Seoul 04620, Korea; yonghan@dgu.edu \\ * Correspondence: yskang7867@gmail.com; Tel.: +82-31-290-7634
}

Received: 4 December 2017; Accepted: 10 January 2018; Published: 13 January 2018

\begin{abstract}
Serialized tracing provides the ability to track and trace the lifecycle of the products and parts. Unlike barcodes, Radio frequency identification (RFID), which is an important building block for internet of things (IoT), does not require a line of sight and has the advantages of recognizing many objects simultaneously and rapidly, and storing more information than barcodes. Therefore, RFID has been used in a variety of application domains such as logistics, distributions, and manufacturing, significantly improving traceability and process efficiency. In this study, we applied RFID to improve the just-in-sequence operation of an automotive inbound logistics process. First, we implemented an RFID-based visibility system for real-time traceability and control of part supply from the production lines of suppliers to the assembly line of a car manufacturer. Second, we developed an RFID-based sequence-error proofing system to avoid accidental line stops due to incorrect part sequencing. The whole system has been successfully installed in a rear-axle inbound logistics process of GM Korea. We achieved a significant amount of cost savings, especially due to the prevention of sequencing errors and part shortages, and the reduction of manual operations. Thorough cost-benefit analysis demonstrates the clear economic feasibility of using RFID technologies for the just-in-sequence inbound logistics in an automobile manufacturing environment.
\end{abstract}

Keywords: RFID; just-in-sequence; inbound logistics; supply chain; automotive manufacturing

\section{Introduction}

Car manufacturers have been attempting to reduce costs and cycle time and increase efficiency by adopting innovative approaches such as make and deliver to order, zero-error-production, lean manufacturing, and just-in-time (JIT) production to survive global competition [1]. One of the recent trends in automobile assembly is to simplify the assembly process by adopting the modularization of parts. Modularization is a production method in which a parts supplier manufactures automobile parts in large units and supplies them to original equipment manufacturers (OEM's). Modularization has a cost-saving effect since the load and production stages of the OEM are reduced because the tasks performed by an OEM, such as design, production, assembly, inspection, and sales, are divided among module production companies. Furthermore, the expertise of parts manufacturers and the proportion of benefits created by them increase.

Meanwhile, against the background of increasingly diverse consumer demands, the manufacturing process in the automobile industry has undergone changes to suit mass customization. That is, the 
number of automobile models has increased, and consumers can choose various customizations for each model. To accommodate the diversification of specifications in the limited assembly lines, the modules and parts of planned specifications have to be fed into the automobile bodies that flow on the assembly line. In general, this work is called sequencing. The purpose of sequencing is to produce and supply the modules and parts according to specification in the exact order required. Today, about $40 \%$ of the parts supplied to automotive OEM's require sequencing [2], and if an error occurs in the sequencing, the assembly line must be stopped, otherwise serious problems such as resupplying or reassembling of the expensive module parts may occur. Therefore, a rigorous process to prevent sequencing errors is very important in the inbound logistics of automobiles.

Thus far, the automobile industry has been using the barcode system to reduce the problems occurring in the supply chain or assembly process such as sequencing. By attaching shipping labels, the accuracy of part recognition and transportation has been increased, misrouting has been reduced, and the accuracy of the location of parts and work in progress has been improved [3]. However, since the barcode system used for preventing sequencing errors involves manual work, human errors can occur, and inefficiency may arise in cases such as when a worker has to manually bring the barcode reader to the location where the barcode tag is attached to check the sequence of individual parts present in containers such as trolleys and boxes.

Radio Frequency Identification (RFID) can solve the problems and overcome the inefficiency of the barcode system. RFID does not require a line of sight and has the advantages that multiple identification is possible and more information can be stored [4]. RFID technology has already been used for various purposes in closed loop applications, and the automobile industry has made considerable investments in RFID technology every year to manage returnable transport items (RTI's) such as racks, totes, and pallets [5]. If RFID can be used to overcome the disadvantages of the barcode system, the object recognition speed may be improved; human errors can be prevented; and the accuracy of information flow and the efficiency of processes will be increased.

With the above considerations, this study aims to develop an RFID infrastructure-based logistics monitoring and sequencing system for reducing sequencing error and sharing real-time inventory information. We implemented and evaluated the latest RFID technologies and standards (in particular, EPCglobal standards) for item-level RFID tracing and sequencing in a manufacturing environment. Furthermore, we analyzed the economic benefits of RFID from the improved inbound logistics visibility and prevented sequencing errors.

\section{Background and Related Works}

\subsection{EPCglobal Network}

We developed the RFID system based on a de-facto standard-EPCglobal standards, so that the system can be easily applied to anonymous supply chain partners. The EPCglobal network is a network of service providers (as subscribers) that follow the EPCglobal architecture framework (Figure 1) on the Internet and the subscribers that use the services specified in the framework. It is a network system that can query the product information, history information, and movement status by automatically recognizing objects using RFID technology and sharing the recognized object information through the Internet. EPC stands for Electronic Produce Code and refers to the standard RFID code system designed by GS1 which is a not-for-profit organisation that develops and maintains global standards for business communication [6]. 


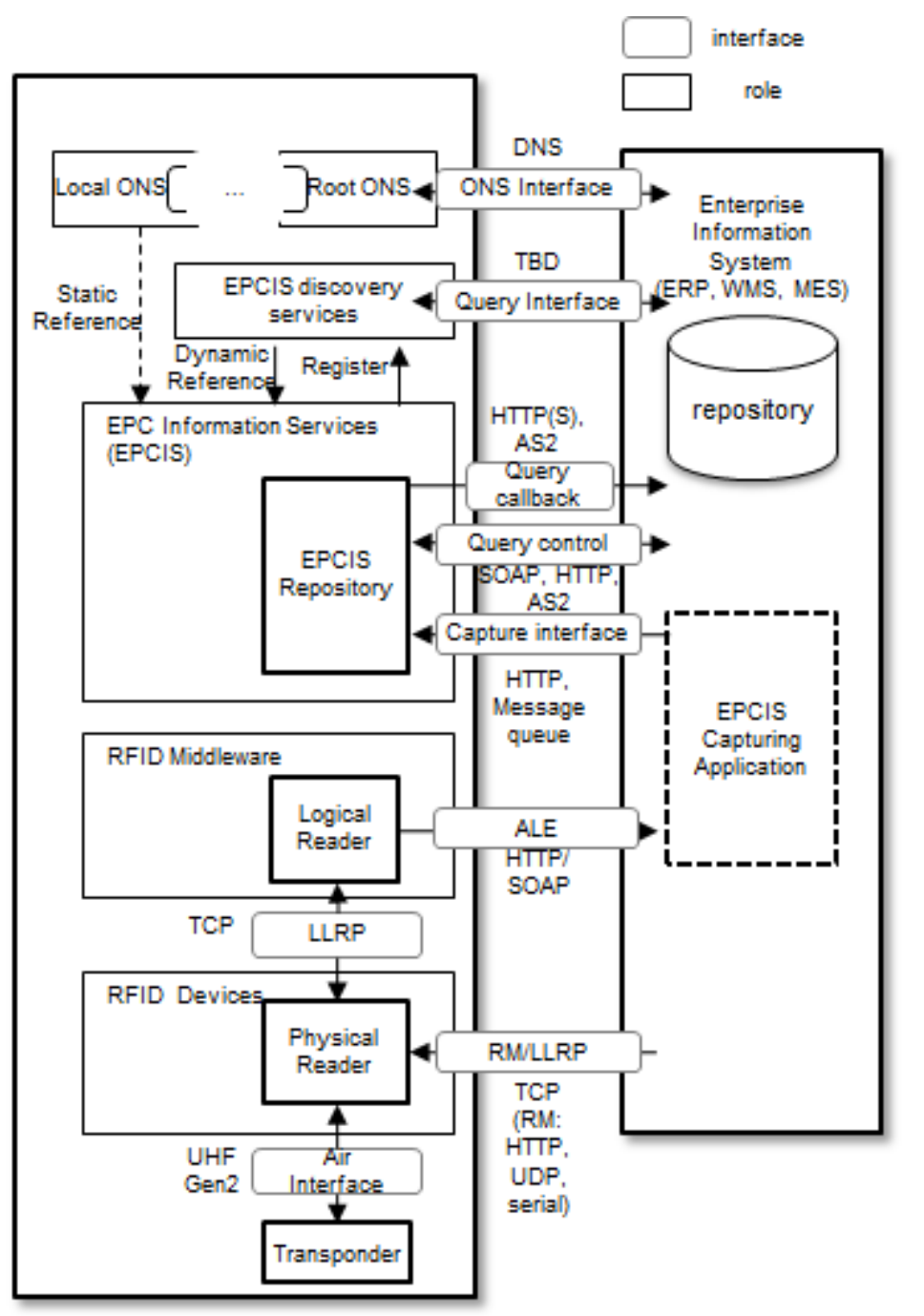

Figure 1. EPCglobal architecture framework (edited from [6]).

The EPCglobal architecture framework comprises three core information services: EPC Information Services (EPCIS), Object Naming Services (ONS), and Discovery Services (DS). These services can be used to secure item traceability and supply chain visibility. A brief description of each service is given below [7].

- EPCIS is a repository of RFID events. It stores the RFID event information in the site and shares the RFID event information between partners. It includes the capture interface for RFID event repository and the query interface for queries; the implementation of repository is vendor-independent.

- ONS provides one or more uniform resource identifiers (URIs) related to EPC, and thus additional information can be acquired through the provided URIs. The provided URIs include the information systems that can provide additional information (product name and manufacture date) of certain EPC or EPCIS and DS for object tracking.

- DS is a service that stores information for the movement of objects among sites. DS stores and shares receiving/shipping events in each site, whereas EPCIS stores the information of RFID events at a site. At present, the development of standards for DS in the concept stage is ongoing. 


\subsection{RFID Applications in Manufacturing}

Various research and development studies on the RFID application in supply chain management have been reported. Vlachos [8] found that RFID applications can significantly improve the performance of distribution systems (by 33.8\%) and stock availability (by 45.6\%). Demiralp et al. [9] demonstrated cost saving opportunities among supply chain partners in the construction supply chain by a simulation study. Poon et al. [10] suggested an RFID-based effective warehouse management system for productivity enhancement and cost saving in warehouse operations by the real-time tracking of warehouse resources. Lee et al. [11] developed an RFID-based resource allocation system for the garment industry, in which the companies need to satisfy rapidly-changing customer demands. They demonstrated that their fuzzy-logic-based resource allocation system driven by the RFID-generated real-time production monitoring information can effectively allocate the materials and facilities in production. Moon et al. [12] utilized RFID systems to track the work efficiency of scaffold suppliers. They verified the benefits of RFID application for a supply chain through performance testing and the field productivity measure. Han and Ko [13] introduced a case of the regional innovation system by applying RFID to a Korean tire company. Oner et al. [14] suggested a roadmap for RFID design, configuration, and deployment, and demonstrated the RFID project using reusable epoxy RFID tags in the denim industry. Economic analysis in [14] has shown that total manpower and lost product costs can be reduced. Ding et al. [15] designed an RFID-based social manufacturing system platform to monitor and dispatch production and transportation tasks in the inter-enterprise and personalized manufacturing environment. They also verified the feasibility and efficiency of the proposed platform by demonstrating examples of real-time data collection, processing, and job monitoring.

In an automotive supply chain, due to the high tag price and the lack of infrastructure, RFID has been used in a 'closed-loop' manner. Accordingly, many reported RFID implementation cases have been in this form [16,17]. Foster et al. [1] suggested a system architecture for an automotive OEM and suppliers to monitor stillages in real-time bases by attaching active RFID tags on high valued stillages for the seamless part supply. Manik et al. [18] pointed out the importance of Auto-ID technologies including RFID in order to solve data integrity problems caused by the manual entry of data in automotive supply-chain operations. In addition, they suggested a cost-benefit analysis model for RFID-system implementation to acquire real-time information of semi-manufactured goods and stock. As noted in previous research, an automotive supply chain consists of many participants. Because of that, for the purpose of operational cost saving, cycle time reduction, and efficiency enhancement, the close collaboration among the participants is a critical factor for success, and can be achieved by RFID-based real-time data exchange [17].

RFID is also important for the manufacturing control. Chongwatpol and Sharda [19] suggested RFID-based real-time scheduling rules which can be applied to shop floors. They proved that the suggested rules are better than traditional methods such as first in first out (FIFO) and earliest due date (EDD) through simulation tests based on real manufacturing process data. Zhong et al. [20] developed a real-time MES framework based on RFID and applied it to mass-customization production shop floors. In addition, they developed a scheduling algorithm using real-time job pools and rules, and proved that the proposed algorithm facilitates real-time work in process control. Barenji et al. [21] proposed an RFID-based multi-agent architecture to design a distributed control and monitoring system for a manufacturing shop. The proposed architecture was proven to show that a set of agents which is deployed to different stations can realize different control, and can provide better productivity than a centralized control system and a distributed control system without RFID. Lee et al. [22] developed an RFID-based process mining system for quality assurance. They used fuzzy association rules to discover the relationship between the process parameters and quality of products. Through a case study in the garment industry, they proved the number of defects, production time, and rework cost were improved. Guo et al. [23] proposed an RFID-based intelligent decision support system to facilitate production monitoring and scheduling in a distributed labor-intensive manufacturing environment. 
The proposed architecture and scheduling model are verified by implementing a pilot system and showing that the system increases production efficiency.

However, most of the existing literatures lack not only detailed information on how to incorporate the characteristics of the implemented sites, but also practical cost-benefit analysis results, thereby failing to help the companies who are considering RFID system implementation in their supply chain operations. In this paper, we suggest a detailed RFID-based information system and data exchange model among supply chain partners, which are appropriate for the characteristics of automotive inbound-logistics processes, focused on just-in-sequence operations.

\section{System Implementation for Serialized Track and Trace}

In this section, we describe the inbound logistics process, which is applied to an RFID system for real-time inventory monitoring and sequencing error prevention, applied hardware, standard information services/applications, and the sequence-checking algorithm that employs RFID.

\subsection{Target Process}

As shown in Figure 2, the entire supply chain comprises three sites: a supplier plant, a consolidation center, and an OEM plant. The target parts are rear axles, and they are supplied to the OEM after sequencing at the consolidation center, which requires attaching of an RFID metal tag at the supplier plant. Visual marks are printed on RFID metal tags so that the types of rear axles can be identified by sequencing workers. The first site, i.e., the supplier plant has three RFID read points: production, 7-rack loading, and shipping. In the 7-rack loading stage, seven rear axles are loaded onto a single 7-rack. At the second site, i.e., the consolidation center, the receiving, stocking, picking, and sequencing stages are conducted. Excluding the stocking stage, the RFID's are read in the other three stages. In the sequencing stage, five parts are loaded on a dolly, which is a portable container. The sequencing workers visually check the marks of RFID metal tags attached at the supplier plant and sequentially load the rear axles on the dollies based on the sequence information provided by the OEM about an hour in advance. Because of the importance of sequencing accuracy, currently, manual inspections are conducted to detect sequencing errors by reading five rear axles on a pertinent dolly with a barcode reader after completing the sequencing; in this study, a system was developed to check the sequencing errors automatically by using an RFID reader. Lastly, at the OEM, four processes, namely, receiving, dolly waiting, dolly towing, and assembly-line feeding, are conducted, and the RFID's are read in the receiving and assembly-line feeding stages only.



Figure 2. The overall supply chain process for rear axles. 


\subsection{System Design and Implementation}

As shown in Figure 3, the structure of the system follows the EPCglobal architecture model, which is a standard model of RFID information services including EPCIS, ONS, and DS. It was completed by additionally developing application programs for production, shipping, receiving, and sequencing.

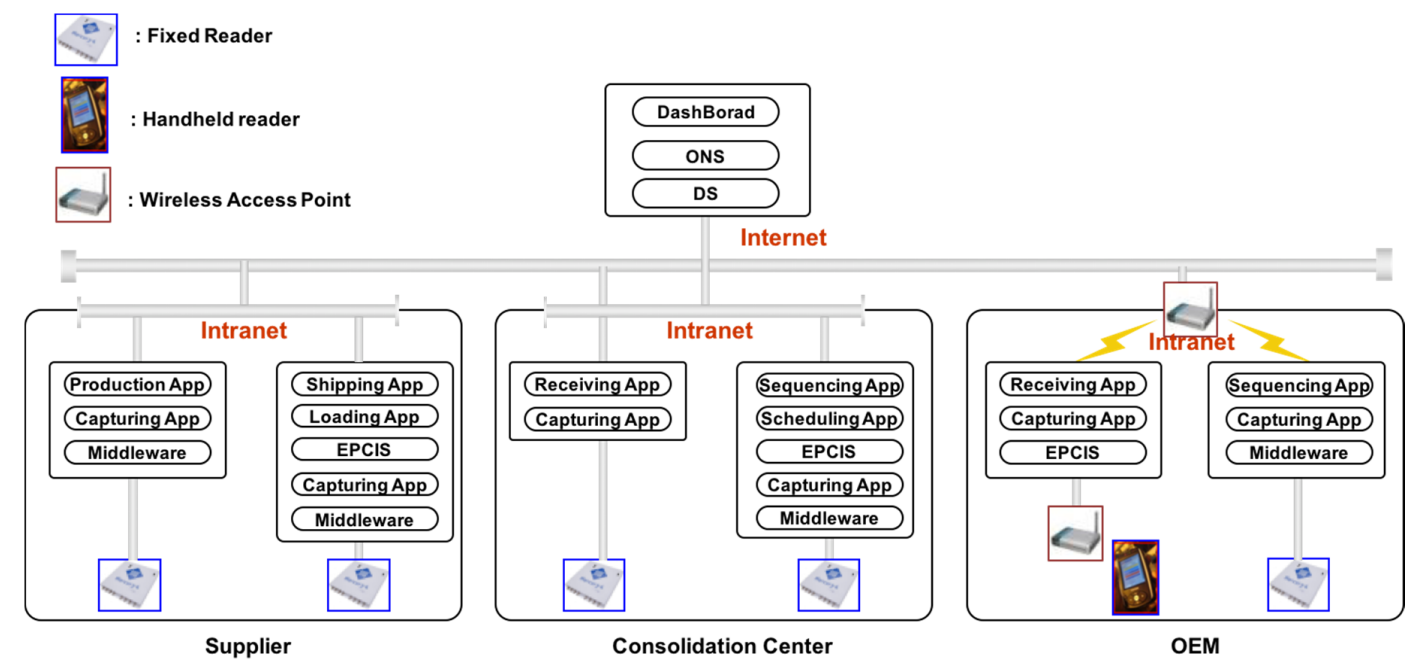

Figure 3. System architecture.

In order to identify RFID tags and store the identification events in the information system, different types of RFID systems and several industrial computers were installed. Table 1 describes the summary of hardware configurations in each read point.

Table 1. Summary of Hardware Configuration.

\begin{tabular}{cccccccc}
\hline & \multicolumn{2}{c}{ Supplier } & \multicolumn{2}{c}{ Consolidation Center } & \multicolumn{2}{c}{ OEM } \\
\hline ReadPoint 1 & ReadPoint 2 & ReadPoint 3 & ReadPoint 4 & ReadPoint 5 & ReadPoint 6 & ReadPoint 7 \\
\hline PC & $\begin{array}{c}\text { Touch-Screen } \\
\text { Monitor, Body, } \\
\text { Speaker }\end{array}$ & $\begin{array}{c}\text { Touch-Screen Monitor, } \\
\text { Body, Speaker }\end{array}$ & $\begin{array}{c}\text { Touch-Screen } \\
\text { Monitor, Body, } \\
\text { Speaker }\end{array}$ & $\begin{array}{c}\text { Touch-Screen } \\
\text { Monitor, Body, } \\
\text { Speaker }\end{array}$ & $\begin{array}{c}\text { Ordinary } \\
\text { Monitor, Body, } \\
\text { Speaker }\end{array}$ & $\begin{array}{c}\text { Touch-Screen } \\
\text { Monitor, Body, } \\
\text { Speaker }\end{array}$ \\
\hline Reader & 900 MHz Fixed Reader & $\begin{array}{c}900 \mathrm{MHz} \\
\text { Fixed Reader }\end{array}$ & $\begin{array}{c}900 \mathrm{MHz} \\
\text { Fixed Reader }\end{array}$ & $\begin{array}{c}900 \mathrm{MHz} \\
\text { Fixed Reader }\end{array}$ & $\begin{array}{c}900 \mathrm{Mhz} \\
\text { Handheld } \\
\text { Reader }\end{array}$ & $\begin{array}{c}900 \mathrm{MHz} \\
\text { Fixed Reader }\end{array}$ \\
\hline Antenna & Linear $\times 1$ & Linear $\times 2$ & Linear $\times 3$ & Linear $\times 1$ & Linear $\times 1$ & & Linear $\times 1$ \\
\hline
\end{tabular}

For stable identification of RFID on the metal, we designed clip-type RFID metal tags and applied them on the top right side of rear axles. In order to reuse the tags, workers at the OEM plant need to detach the tags before assembly-line feeding and return them to the supplier plant via delivery trucks returning with the empty racks. Figure 4 shows the detailed specification and shape of the metal tags.

For the rear axles produced at the supplier plant, the RFID's are read through the RFID antenna shown in Figure 5a, and the ID's are stored in the EPCIS. In addition, the rear axles are loaded onto the 7-racks after production (Figure 5b), and here, their parent-child relationships (parent: rack's ID, children: rear axles' ID) are also stored in the EPCIS. The production and 7-rack loading processes can be monitored by workers through the production monitoring application shown in Figure $5 \mathrm{c}$.

When shipping, the ID's of the 7-racks loaded onto the forklift in three layers are checked with the RFID antennas shown in Figure 6a, and by querying the EPCIS about the ID's with the parent keys (i.e., ID of the 7-rack), the ID's of individual rear axles on the pertinent 7-racks are queried. Thereafter, the ID's of the rear axles are immediately stored again in the EPCIS, and the shipping process is completed. Figure 7 depicts the data flows between EPCIS and the capturing application, and shows 
sample messages of the EPCIS query and query result for retrieving the information of the rear axles in a 7-rack. Furthermore, the shipped parts and 7-rack ID's can be checked by the workers through the shipping monitoring application shown in Figure $6 \mathrm{~b}$.

\begin{tabular}{|c|c|c|}
\hline Category & Specification & Image \\
\hline Frequency & $902 \sim 928 \mathrm{MHz}$ & \\
\hline Protocol & EPC Class 1 Gen2 & \\
\hline Type & Mount On Metal & \\
\hline Memory & 96 Bit & \\
\hline Dimensions & $84 \times 30 \times 5 \mathrm{~mm}$ & \\
\hline Chip Attached & Direct Bonding & \\
\hline Attachment & VHB (Double side adhesive) & \\
\hline Packaging Material & ABS & \\
\hline $\begin{array}{l}\text { Operating } \\
\text { temperature }\end{array}$ & "-"20 $20^{\circ} \sim+70^{\circ} \mathrm{C}$ & \\
\hline $\begin{array}{l}\text { Operating } \\
\text { temperature }\end{array}$ & "-"20 2 C + $85^{\circ} \mathrm{C}$ & \\
\hline Heat resistance & "+"130 C $10 \mathrm{~min}$ & \\
\hline Cold resistance & "-"200 $\mathrm{C}$ & \\
\hline Thermal cycle resistance & 200 Cycle $"-" 20^{\circ} \mathrm{C} \sim+75^{\circ} \mathrm{C}$ & \\
\hline $\begin{array}{l}\text { Temperature humidity } \\
\text { resistance }\end{array}$ & $60^{\circ} \mathrm{C}, 85 \mathrm{RH}, 168 \mathrm{~h}$ & \\
\hline ESD voltage immunity & "+l- 2kV peak" & \\
\hline Storage & $\begin{array}{l}"+15^{\circ} \mathrm{C} \sim+25^{\circ} \mathrm{C}, 40 \sim 60 \% \mathrm{RH}, \max 2 \\
\text { years }\end{array}$ & \\
\hline Memory storage & 10 years & \\
\hline Static pressure & $10 \mathrm{Mpa}\left(10 \mathrm{~N} / \mathrm{mm}^{\prime}\right)$ & \\
\hline
\end{tabular}

Figure 4. Specification of radio frequency identification (RFID) metal tag.

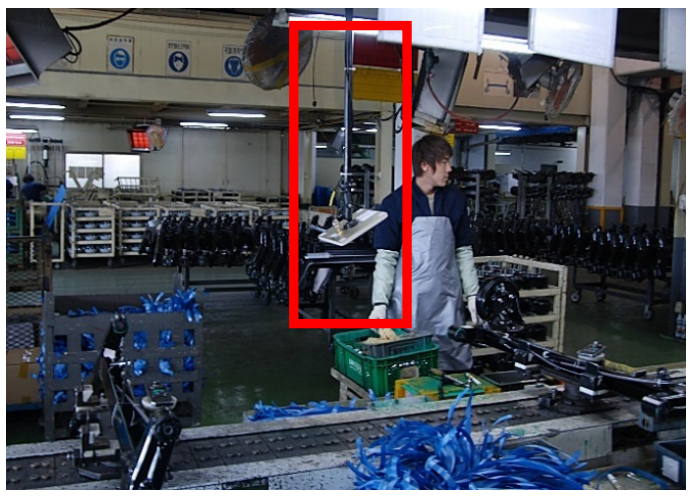

(a)

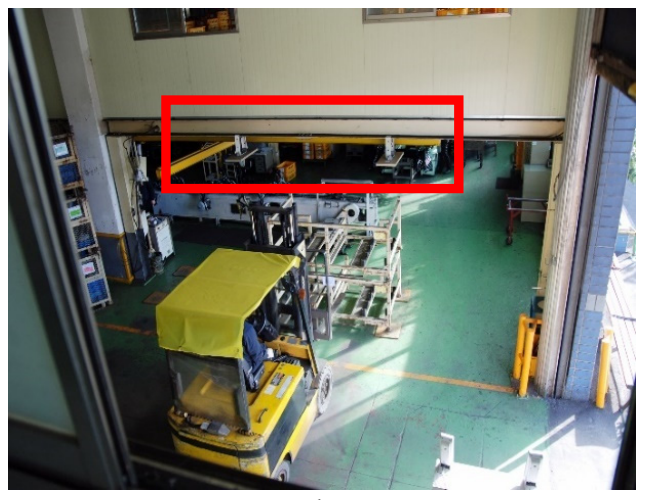

(b)

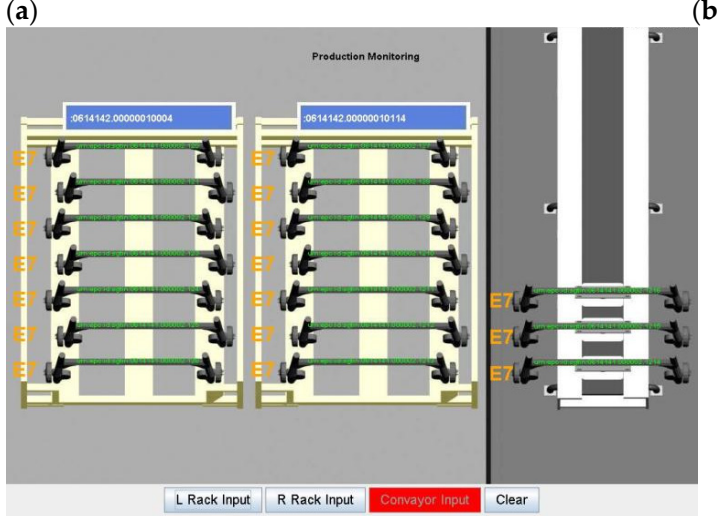

(c)

Figure 5. Production monitoring in the supplier plant. (a) Read point at production line; (b) Read point at 7-rack loading area; (c) Screen shot of production monitoring application. 




(a)

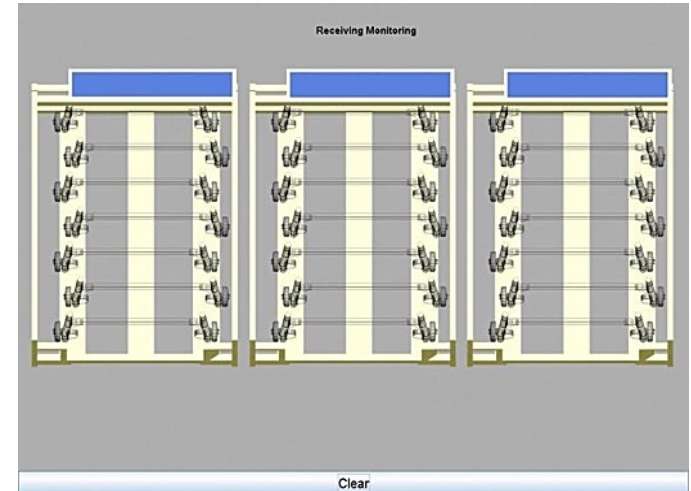

(b)

Figure 6. The shipping process at the supplier plant. (a) Read point at shipping area; (b) Screen shot of shipping application.

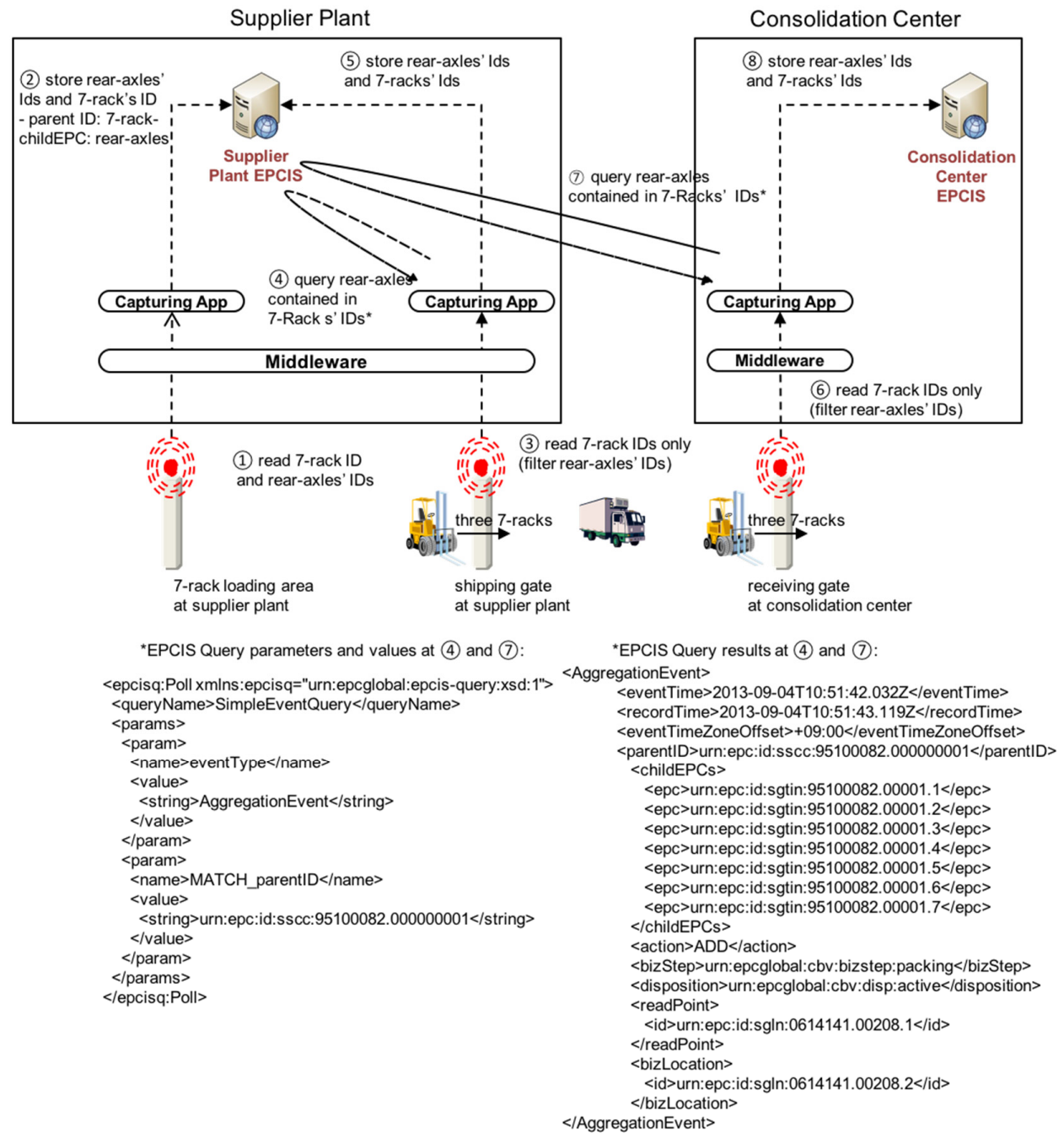

Figure 7. Electronic product code information services (EPCIS) query and query result at shipping and receiving processes.

When the rear axles arrive at the consolidation center, an information flow similar to that of the shipping process at the supplier plant is created. As shown in Figure 8a, the ID's of the 7-racks loaded in three layers are read, and after fetching the ID's of the children rear axles by querying the supplier 
plant's EPCIS about the ID's of the 7-rack with the parent key (at (7) in Figure 7), the receiving process is carried out by storing the ID's of rear axles in the consolidation center's EPCIS. As in the previous stage, the workers can monitor the receiving status through an application shown in Figure 8b.

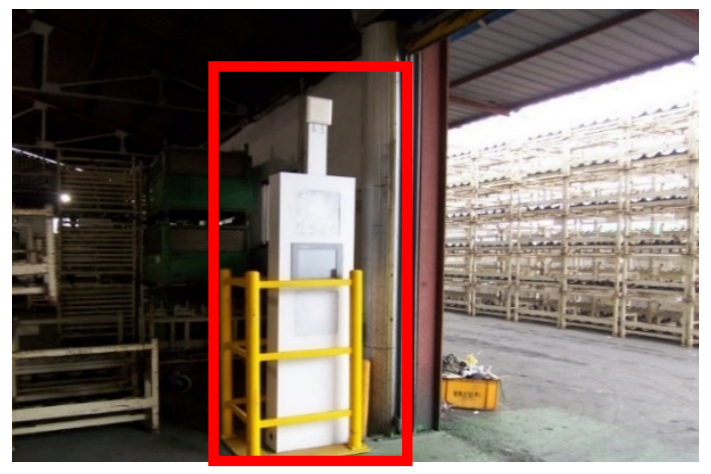

(a)

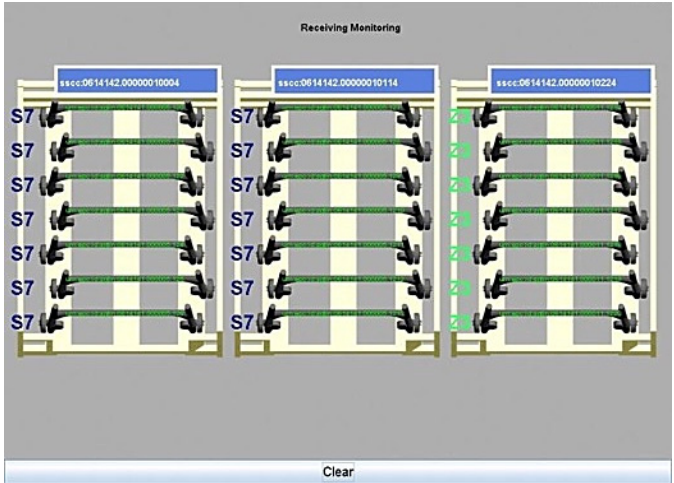

(b)

Figure 8. The receiving process at the consolidation center. (a) Read point at receiving area; (b) Screen shot of receiving application.

For the automobile bodies that have undergone the painting process at the OEM, the final assembly sequences are determined, and here, the sequence information is sent to the supplier's consolidation center through a dedicated communication line. After the workers load the rear axles onto the dollies at the consolidation center according to the sequence information, the accuracy of the sequences is checked by comparing the sequence information collected through the RFID as they pass through the RFID-based sequence-checking device and the sequence information received from the OEM. When a dolly towed by a worker passes through the sequence-checking device as shown in Figure 9a, the inspection process is automatically conducted. Here, since the inspection result is displayed on the screen of the checking device via the application shown in Figure $9 b, c$, and since the appropriate sound signal is generated, the worker receives the examination result immediately.

After the dollies containing the rear axles arrive at the OEM plant, dolly sequencing is carried out when they are fed to the assembly line. The order in which the dollies are fed is checked (the sequences of the rear axles loaded on the dollies have already been checked at the consolidation center) using the equipment shown in Figure 10a to prevent any sequencing errors. Figure 10b,c represent the screen shots of the dolly sequencing application in the cases of both no-error and error.

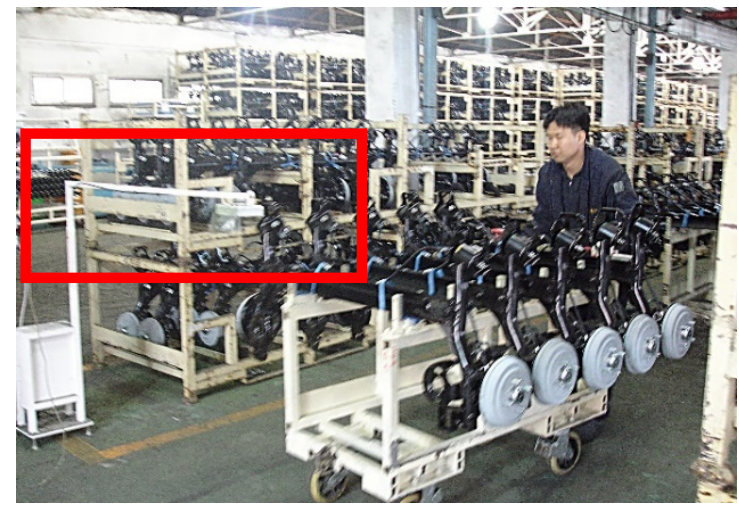

(a)

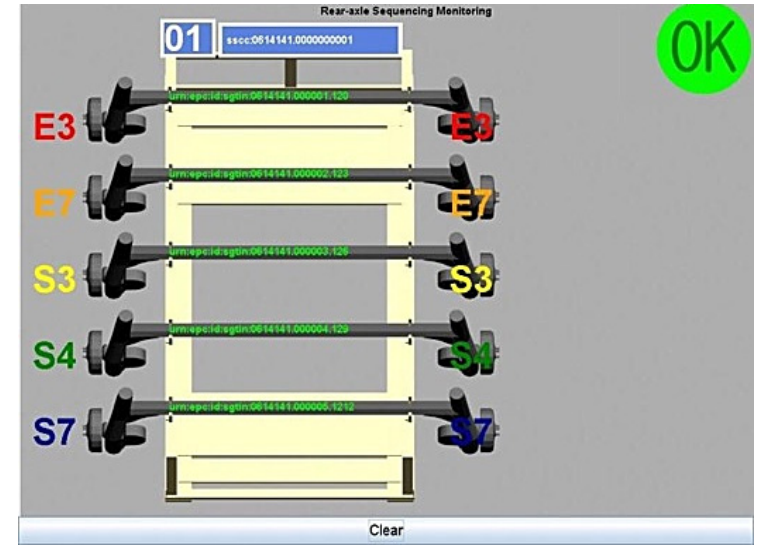

(b)

Figure 9. Cont. 


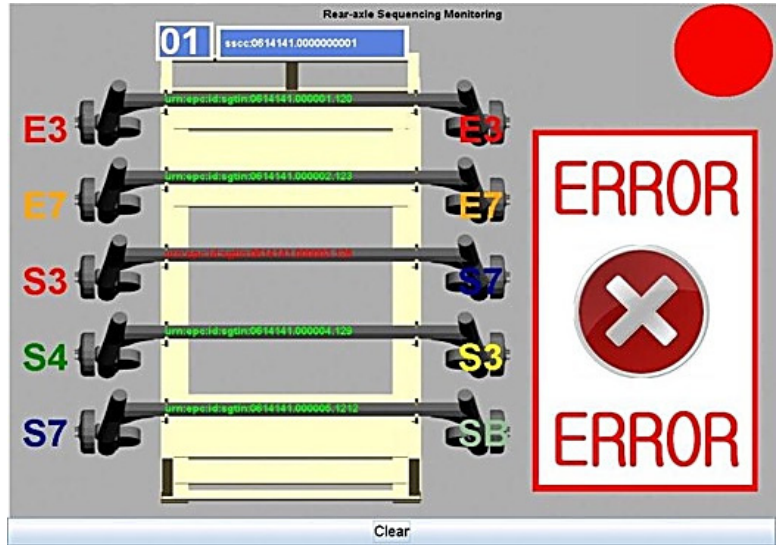

(c)

Figure 9. The sequencing process at the consolidation center. (a) Read point at sequencing area; (b) Screen shot of sequencing application in the case of no-error; (c) Screen shot of sequencing application in the case of sequencing-error.

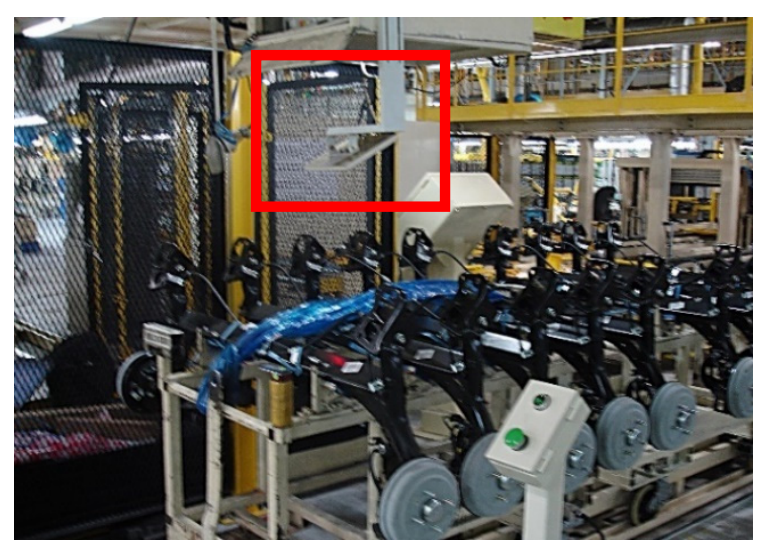

(a)



(b)

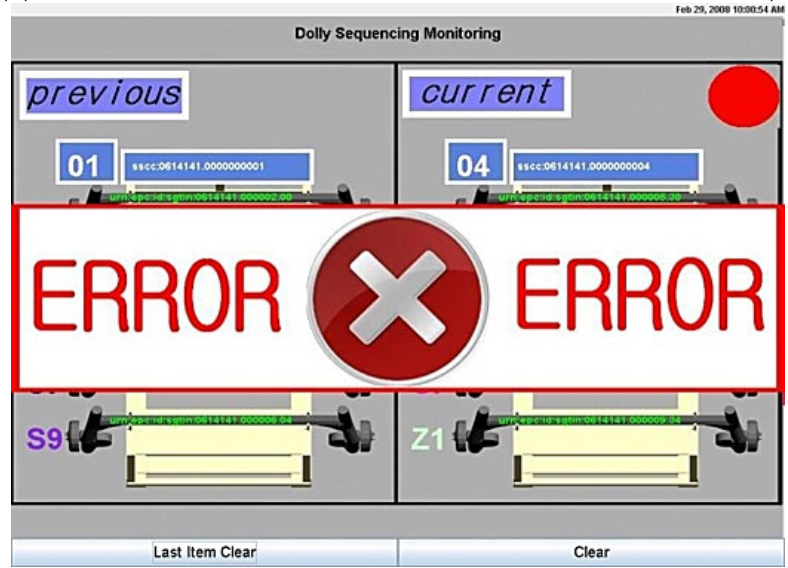

(c)

Figure 10. The sequencing process at the OEM. (a) Read point at feeding area; (b) Screen shot of dolly sequencing application in the case of no-error; (c) Screen shot of dolly sequencing application in the case of sequencing-error.

The constructed RFID system facilitates not only sequence checking but also real-time inventory monitoring, as shown in Figure 11. The pertinent application aggregates and reports current inventory 
information based on the receiving or shipping RFID event data stored in the EPCIS installed at each site. The inventory at each plant can be monitored automatically from an office instead of having workers at the consolidation center check the inventory every morning and share the inventory information with the managers so that they can plan the daily production schedule of the supplier plant. Consequently, the inventory-checking time of workers at the consolidation center and the inventory errors are reduced, and real-time production planning and inventory control become possible.

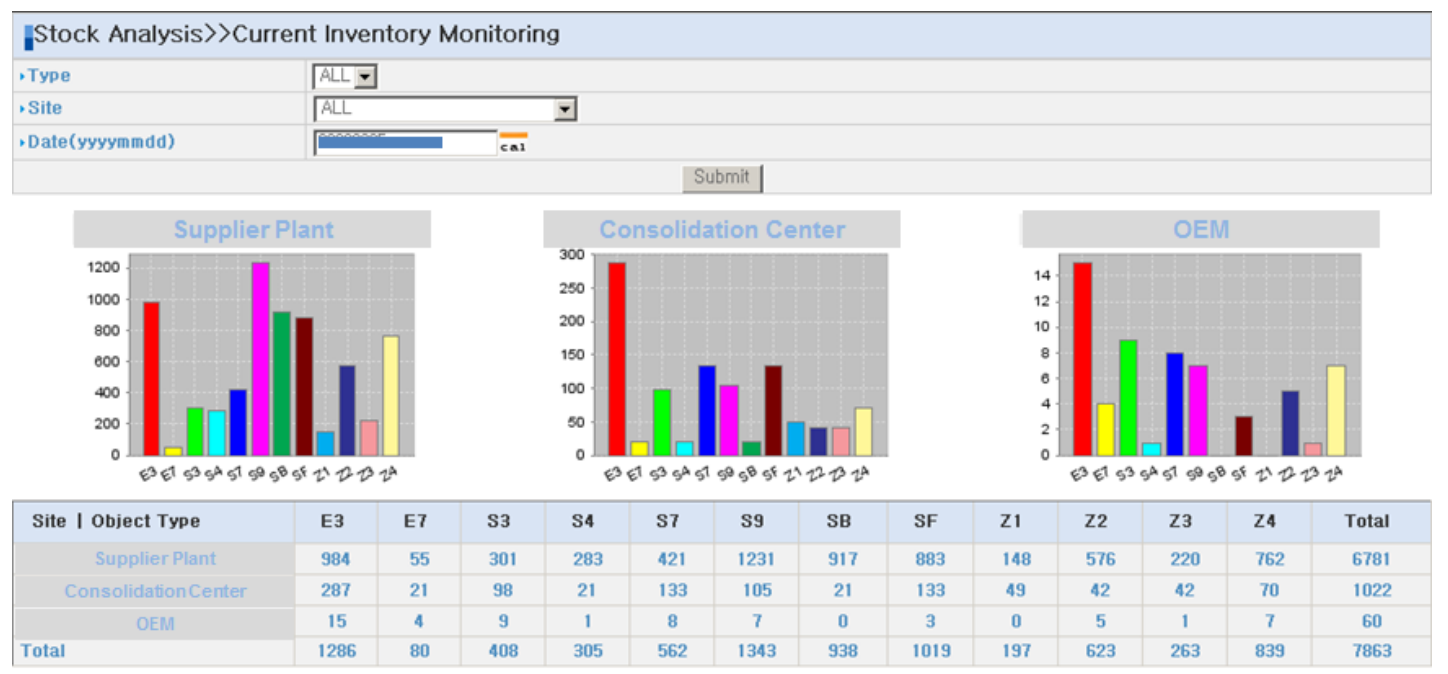

Figure 11. The real-time inventory monitoring application.

\subsection{Sequence-Checking Algorithm}

Regular RFID antennas are designed for recognizing several tags simultaneously. In other words, they are designed to read as many tags as possible within the recognition range. However, if the regular antennas are used as they are in the sequencing work, the tags cannot be read in an orderly manner, and sequencing errors cannot be determined accurately. In order to recognize the correct sequence of RFIDs in a row, we used an RFID sequence-checking algorithm which is proposed in [23]. The algorithm is based on the read frequency (i.e., the number of successful reads in a predefined cycle time). Figure 12 summarizes the sequence-checking algorithm for RFID. The basic concept of this algorithm is that as the rear axles loaded onto the dolly sequentially pass through the RFID sequence-checking device, the reading sequence is determined by considering the average of the RFID read times. While a dolly passes through the sequence-checking zone, the reader repeats read cycles, during each of which the reader can read the ID's multiple times (called read count). The read counts of each ID over the repeating read cycles generate a time-domain profile of read counts. Sometimes the rear axles placed in the back of the dolly are read before those placed in the front, but in this case, the recognition frequency (the number of successful reads) is very low. Therefore, the average read time values can clearly determine the sequence of RFID tags. The robustness of this algorithm was verified through experiments in [24]. 




Figure 12. The sequence-checking algorithm.

\section{Analysis of the Economic Effect}

To analyze the economic effect of the RFID system developed in this study, the major benefits were determined through interviews with the managers of production management departments. The benefits included (1) prevention of sequencing errors; (2) prevention of the shortage of certain specification parts; and (3) reduction of the labor costs incurred for checking sequencing errors. In particular, the cost incurred by the shutdown of the production line because of sequencing errors can be calculated by the following two methods.

- Direct shutdown cost estimation estimates a direct opportunity cost incurred by the shutdown. The dominant cost factor is the labor cost of about 120 workers deployed to the pertinent automobile body production line, and the official shutdown cost defined by the OEM is $\$ 370$ per minute.

- Comprehensive shutdown cost estimation refers to the comprehensive cost estimation that includes the loss of sales opportunities. This cost estimation method is generally used in production environments in North American regions.

The cost-saving effects were estimated according to the above two methods. A detailed description of the analysis is presented in Tables 2 and 3, which summarize the results of calculating the annual cost-saving effect with the direct shutdown cost estimation and comprehensive cost estimation methods, respectively. We applied two scenarios to each cost estimation method. In the first scenario, five shutdowns occur annually, and the inventory is reduced by $10 \%$; in the second scenario, seven shutdowns occur annually, and the inventory is reduced by $20 \%$. The analysis results showed that when the system was applied to three parts (instrumental panel, seats, and rear axles) at three plants, the annual cost saving amounted to $\$ 14.1$ million and $\$ 19.5$ million for the first and second scenarios, respectively, according to the comprehensive shutdown cost estimation. 
Table 2. Direct shutdown cost estimation (unit \$: USD).

\begin{tabular}{|c|c|c|c|c|}
\hline & Stretched Scenario & & Conservative Scenario & \\
\hline Category & Reasoning & Amount & Reasoning & Amount \\
\hline $\begin{array}{l}\text { (1) Annual shutdown } \\
\text { cost saving }\end{array}$ & $\begin{array}{l}7 \text { time } / \text { year } \times 30 \mathrm{~min} \\
\times \$ 370 \\
\text { shutdown-cost } / \mathrm{min}\end{array}$ & $\$ 77,700$ & $\begin{array}{l}5 \text { time } / \text { year } \times 30 \mathrm{~min} \\
\times \$ 370 \\
\text { shutdown-cost } / \mathrm{min}\end{array}$ & $\$ 55,500$ \\
\hline \multicolumn{5}{|l|}{$\begin{array}{l}\text { (2) Annual labour } \\
\text { cost saving }\end{array}$} \\
\hline $\begin{array}{l}(2-1) \text { Data collection } \\
\text { time/information } \\
\text { processing time/inventory } \\
\text { tracking time/lead-time } \\
\text { reduction }\end{array}$ & $\begin{array}{l}250 \text { day } / \text { year } \times \\
2 \text { people } \times \\
\$ 65 \text { cost/day }\end{array}$ & $\$ 32,500$ & $\begin{array}{l}250 \text { day } / \text { year } \times \\
2 \text { people } \times \\
\$ 65 \text { cost/day }\end{array}$ & $\$ 32,500$ \\
\hline $\begin{array}{l}\text { (2-2) Data collection } \\
\text { time/information } \\
\text { processing time/inventory } \\
\text { tracking time }\end{array}$ & $\begin{array}{l}250 \text { day } / \text { year } \times \\
2 \text { people } \times \\
\$ 65 \text { cost/day }\end{array}$ & $\$ 32,500$ & $\begin{array}{l}250 \text { day } / \text { year } \times \\
2 \text { people } \times \\
\$ 65 \text { cost/day }\end{array}$ & $\$ 32,500$ \\
\hline $\begin{array}{l}\text { (3) Annual inventory } \\
\text { cost saving }\end{array}$ & $\begin{array}{l}\text { The reduction of safety } \\
\text { stock by } 20 \% ; 1950 \text { rear } \\
\text { axle/day } \times 20 \% \\
\text { (reduction rate) } \times \$ 150 \\
\text { /rear axle } \times 0.08 \\
\text { interest-rate/year }\end{array}$ & $\$ 4680$ & $\begin{array}{l}\text { The reduction of safety } \\
\text { stock by } 10 \% ; 1950 \text { rear } \\
\text { axle/day } \times 10 \% \\
\text { (reduction rate) } \times \\
\$ 150 / \text { rear axle } \times 0.08 \\
\text { interest-rate/year }\end{array}$ & $\$ 2340$ \\
\hline \multicolumn{2}{|c|}{ (4) Annual cost saving for rear axles only } & $\$ 147,380$ & & $\$ 122,840$ \\
\hline \multicolumn{2}{|c|}{$\begin{array}{l}\text { (5) Case-1: three assembly line items } \\
\text { (instrumental panel, seats, and rear axles) }\end{array}$} & $\$ 442,140$ & & $\$ 368,520$ \\
\hline \multicolumn{2}{|l|}{ (6) Case-2: three plants } & $\$ 1,326,420$ & & $\$ 1,105,560$ \\
\hline
\end{tabular}

Table 3. Comprehensive shutdown cost estimation (unit \$: USD).

\begin{tabular}{|c|c|c|c|c|}
\hline & Stretched Scenario & & Conservative Scenario & \\
\hline Category & Reasoning & Amount & Reasoning & Amount \\
\hline $\begin{array}{l}\text { (1) Annual shutdown cost } \\
\text { saving }\end{array}$ & $\begin{array}{l}7 \text { time } / \text { year } \times 30 \mathrm{~min} \\
\times \$ 10,000 \\
\text { shutdown-cost } / \mathrm{min}\end{array}$ & $\$ 77,700$ & $\begin{array}{l}5 \text { time } / \text { year } \times 30 \mathrm{~min} \\
\times \$ 10,000 \\
\text { shutdown-cost } / \mathrm{min}\end{array}$ & $\$ 1,500,000$ \\
\hline \multicolumn{5}{|l|}{$\begin{array}{l}\text { (2) Annual labour cost } \\
\text { saving }\end{array}$} \\
\hline $\begin{array}{l}\text { (2-1) Data collection } \\
\text { time/information } \\
\text { processing time/inventory } \\
\text { tracking time/lead-time } \\
\text { reduction }\end{array}$ & $\begin{array}{l}250 \text { day } / \text { year } \times \\
2 \text { persons } \times \\
\$ 65 \text { cost/day }\end{array}$ & $\$ 32,500$ & $\begin{array}{l}250 \text { day } / \text { year } \times \\
2 \text { people } \times \\
\$ 65 \text { cost/day }\end{array}$ & $\$ 32,500$ \\
\hline $\begin{array}{l}\text { (2-2) Data collection } \\
\text { time/information } \\
\text { processing time/inventory } \\
\text { tracking time }\end{array}$ & $\begin{array}{l}250 \text { day } / \text { year } \times \\
2 \text { people } \times \\
\$ 65 \text { cost/day }\end{array}$ & $\$ 32,500$ & $\begin{array}{l}250 \text { day } / \text { year } \times \\
2 \text { people } \times \\
\$ 65 \text { cost/day }\end{array}$ & $\$ 32,500$ \\
\hline $\begin{array}{l}\text { (3) Annual inventory cost } \\
\text { saving }\end{array}$ & $\begin{array}{l}\text { The reduction of safety } \\
\text { stock by } 20 \% ; 1950 \text { rear } \\
\text { axle/day } \times 20 \% \\
\text { (reduction rate) } \times \$ 150 \\
\text { /rear axle } \times 0.08 \\
\text { interest-rate/year }\end{array}$ & $\$ 4680$ & $\begin{array}{l}\text { The reduction of safety } \\
\text { stock by } 10 \% ; 1950 \text { rear } \\
\text { axle/day } \times 10 \% \\
\text { (reduction rate) } \times \\
\$ 150 / \text { rear axle } \times 0.08 \\
\text { interest-rate/year }\end{array}$ & $\$ 2340$ \\
\hline \multicolumn{2}{|c|}{ (4) Annual cost saving for rear axles only } & $\$ 2,169,680$ & & $\$ 1,567,340$ \\
\hline \multicolumn{2}{|c|}{$\begin{array}{l}\text { (5) Case-1: three assembly line items } \\
\text { (instrumental panel, seats, and rear axles) }\end{array}$} & $\$ 6,509,540$ & & $\$ 4,702,020$ \\
\hline \multicolumn{2}{|l|}{ (6) Case-2: three plants } & $\$ 19,527,120$ & & $\$ 14,106,060$ \\
\hline
\end{tabular}




\section{Conclusions}

Automobile manufacturers source materials and goods from various supply-chain partners. An automobile has about 25,000 parts, and numerous companies such as suppliers, logistics service providers, OEM's, dealers, and garages participate and collaborate in an automotive supply chain. Because of such a complexity of the auto-part supply chain processes, damages, losses, and wrong deliveries often occur, and there are even difficulties in identifying when and where the problems occurred.

In this study, an RFID system was developed to share real-time inventory information and to prevent sequencing errors, which are a type of wrong delivery: they are tremendously important issues in the automotive supply chain process. An RFID system was developed based on an RFID standard information infrastructure called the EPCglobal network, and the standard system helps flexible information sharing between companies, fast system extension, and flexible responses to vendor replacements. Furthermore, in this study, we analyzed the economic effect of implementing the RFID system. By calculating the opportunity costs for annual shutdowns, we analyzed the economic effects of reducing sequencing errors and sharing inventory information.

This paper contributes several aspects related to RFID applications in manufacturing and supply chain fields. First, while most previous studies have demonstrated the benefits of RFID using pilot tests, lab tests, and mathematical models, this study presented the actual economic effect of implementing RFID in the companies that are hesitant to use RFID technology because of its as yet uncertain expected economic benefits. Second, this paper used de-facto standards to implement RFID hardware and software systems in the real supply chain. It provides the feasibility of implementing standardized RFID systems in a supply chain which is composed of different companies. Third, this study showed that the hardware limitations of RFID can be overcome by software algorithms such as the sequence-checking algorithm. Therefore, we believe that the results of this study will contribute to increased RFID implementation in the field of manufacturing logistics.

Although this study analyzed the economic benefits of RFID from the improved inbound logistics visibility and prevented sequencing errors, a quantitative cost-benefit analysis such as return on investment (ROI) analysis and break-even point analysis was not presented. Future studies need to conduct a cost-benefit analysis that takes into account initial investment costs and maintenance costs. In addition, from a cost-benefit perspective, comparative studies between RFID and other technologies are required.

Despite the various advantages of RFID, the increase in its application is slower compared to that of barcodes. Particularly, in the case of the manufacturing industry, it is difficult to implement an open supply chain because the code structure and information system structure differ among car manufacturers. Nevertheless, most suppliers in the automotive industry are supplying products to one or more OEM's, and this implies that according to the system changes in each OEM, the systems of suppliers have to be changed, which will incur high costs. In the future, these problems need to be solved through the participation of all supply chain members who must take cooperative approaches of sharing profits and costs, for example, by interactively constructing a flexible standard system such as the EPCglobal network, between OEM's and suppliers.

Acknowledgments: This work was supported by the GM Research Fund (PO: TCS06344) and the Basic Science Research Program through the National Research Foundation of Korea (NRF) funded by the Ministry of Education (NRF-2016R1A6A3A11930205). This paper is a tribute of deep respect and memory of a wonderful person, friend, engineer, and professor, Yong-Han Lee.

Author Contributions: Yong-Shin Kang designed the system architecture and implemented the applications; Hyoennam Kim designed and implemented the error proofing system; Yong-Han Lee designed the overall research structure and led the project.

Conflicts of Interest: The authors declare no conflict of interest. 


\section{References}

1. Foster, P.; Sindhu, A.; Blundell, D. A case study to track high value stillages using RFID for an automobile OEM and its supply chain in the manufacturing industry. In Proceedings of the 2006 IEEE International Conference on Industrial Informatics, Singapore, 16-18 August 2006; pp. 56-60.

2. Wagner, S.; Silveira-Camargos, V. Decision model for the application of just-in-sequence. Int. J. Prod. Res. 2011, 49, 5713-5736. [CrossRef]

3. Schmitt, P.; Michahelles, F.; Fleisch, E. Why RFID Adoption and Diffusion Takes Time: The Role of Standards in the Automotive Industry; White Paper; Auto-ID Labs: Cambridge, MA, USA, 2008.

4. Karygiannis, T.; Eydt, B.; Barber, G.; Bunn, L.; Phillips, T. Guidelines for Securing Radio Frequency Identification (RFID) Systems; NIST Special Publication: Gaithersburg, MD, USA, 2007; Volume 80.

5. Zaino, J. Car Makers Steer toward RFID. RFID J. Emerald Expositions, LLC., 4 March 2013; pp. 25-30. Available online: https: / / www.rfidjournal.com/purchase-access?type=Article\&id=10481\&r=\%2Farticles \% 2Fview\%3F10481 (accessed on 12 January 2018).

6. Thiesse, F.; Floerkemeier, C.; Harrison, M.; Michahelles, F.; Roduner, C. Technology, Standards, and Real-World Deployments. IEEE Internet Comput. 2009, 13, 36-43. [CrossRef]

7. Traub, K. (Ed.) The EPCglobal Architecture Framework Version 1.4; Ratified Standard; EPCglobal: Beijing, China, 2010.

8. Vlachos, I. A hierarchical model of the impact of RFID practices on retail supply chain performance. Expert Syst. Appl. 2014, 41, 5-15. [CrossRef]

9. Demiralp, G.; Guven, G.; Ergen, E. Analyzing the benefits of RFID technology for cost sharing in construction supply chains: A case study on prefabricated precast components. Autom. Constr. 2012, 24, 120-129. [CrossRef]

10. Poon, T.; Choy, K.; Chow, H.; Lau, H.; Chan, F.; Ho, K. A RFID case-based logistics resource management system for managing order-picking operations in warehouses. Expert Syst. Appl. 2009, 36, 8277-8301. [CrossRef]

11. Lee, C.; Choy, K.; Ho, G.; Lay, K. A RFID-based resource allocation system for garment manufacturing. Expert Syst. Appl. 2013, 40, 784-799. [CrossRef]

12. Moon, S.; Xu, S.; Hou, L.; Wu, C.; Wang, X.; Tam, V.W. RFID-Aided Tracking System to Improve Work Efficiency of Scaffold Supplier: Stock Management in Australasian Supply Chain. J. Constr. Eng. Manag. 2017, 144, 04017115. [CrossRef]

13. Han, J.; Ko, Y. Knowledge exploitation and entrepreneurial activity in a regional innovation system: First adaption of RFID at Kumho Tire in GwangJu, Korea. Eur. Plan. Stud. 2017, 25, 867-885. [CrossRef]

14. Oner, M.; Ustundag, A.; Budak, A. An RFID-based tracking system for denim production processes. Int. J. Adv. Manuf. Technol. 2017, 90, 591-604. [CrossRef]

15. Ding, K.; Jiang, P.; Su, S. RFID-enabled social manufacturing system for inter-enterprise monitoring and dispatching of integrated production and transportation tasks. Robot. Comput.-Integr. Manuf. 2018, 49, 120-133. [CrossRef]

16. Khan, O.; Scotti, A.; Leverano, A.; Bonino, F.; Ruggiero, G.; Dörsch, C. RFID in automotive: A closed-loop approach. In Proceedings of the 12th International Conference on Concurrent Enterprising, Milano, Italy, 26-28 June 2006.

17. Schmitt, P.; Thiesse, F.; Fleisch, E. Adoption and diffusion of RFID technology in the automotive industry. In Proceedings of the 15th European Conference on Information Systems (ECIS), St. Gallen, Switzerland, 7-9 June 2007.

18. Manik, D.; Toth, L.; Dobrossy, P. Analysis of RFID application through an automotive supplier's production processes. In Proceedings of the International Symposium on Computational Intelligence and Intelligent Informatics (ISCIII 2007), Agadir, Morocco, 28-30 March 2007; pp. 177-181.

19. Chongwatpol, J.; Sharda, R. RFID-enabled track and traceability in job-shop scheduling environment. Eur. J. Oper. Res. 2013, 227, 453-463. [CrossRef]

20. Zhong, R.Y.; Dai, Q.Y.; Qu, T.; Hu, G.J.; Huang, G.Q. RFID-enabled real-time manufacturing execution system for mass-customization production. Robot. Comput.-Integr. Manuf. 2013, 29, 283-292. [CrossRef]

21. Barenji, R.V.; Barenji, A.V.; Hashemipour, M. A multi-agent RFID-enabled distributed control system for a flexible manufacturing shop. Int. J. Adv. Manuf. Technol. 2014, 71, 1773-1791. [CrossRef] 
22. Lee, C.K.H.; Ho, G.T.S.; Choy, K.L.; Pang, G.K.H. A RFID-based recursive process mining system for quality assurance in the garment industry. Int. J. Prod. Res. 2014, 52, 4216-4238. [CrossRef]

23. Guo, Z.X.; Ngai, E.W.T.; Yang, C.; Liang, X. An RFID-based intelligent decision support system architecture for production monitoring and scheduling in a distributed manufacturing environment. Int. J. Prod. Econ. 2015, 159, 16-28. [CrossRef]

24. Jin, H.-J.; Kim, H.; Lee, Y.-H. A Context-Aware System for Reliable RFID-based Logistics Management. J. Soc. e-Bus. Stud. 2013, 18, 223-240. [CrossRef]

(C) 2018 by the authors. Licensee MDPI, Basel, Switzerland. This article is an open access article distributed under the terms and conditions of the Creative Commons Attribution (CC BY) license (http:/ / creativecommons.org/licenses/by/4.0/). 